\title{
Differential Tolerance to Lead and Cadmium of Micropropagated Gypsophila fastigiata Ecotype
}

\author{
Ewa Muszyńska (D) Ewa Hanus-Fajerska • \\ Aleksandra Koźmińska
}

Received: 4 November 2017 / Accepted: 11 January 2018 / Published online: 25 January 2018

(C) The Author(s) 2018. This article is an open access publication

\begin{abstract}
In vitro techniques may provide a suitable tool for effective propagation and conservation of plant species representing various ecological niches. The elaboration of such protocols is also prerequisite for selection of heavy-metal-tolerant plant material that could be afterwards used for restoration or remediation of polluted sites. In this study, culture protocol for Gypsophila fastigiata propagation was developed. The highest multiplication coefficient, which reached 6.5 , and the best growth parameters were obtained on modified MS medium supplemented with $1.0 \mathrm{mg} \mathrm{L}^{-1} 2 \mathrm{iP}$ and $0.2 \mathrm{mg} \mathrm{L}^{-1}$ IAA. The obtained cultures were treated with different concentrations of lead nitrate $(0.1,0.5$, and $\left.1.0 \mathrm{mM} \mathrm{Pb}\left(\mathrm{NO}_{3}\right)_{2}\right)$ or cadmium chloride $(0.5,2.5$, and $5.0 \mu \mathrm{M} \mathrm{CdCl}_{2}$ ). The growth parameters, photosynthetic pigments, and phenolic compound content were examined in order to evaluate whether tested metal salts can have an adverse impact on studied culture. It was ascertained that $\mathrm{Pb}$ ions induced growth disturbances
\end{abstract}

Electronic supplementary material The online version of this article (https://doi.org/10.1007/s11270-018-3702-8) contains supplementary material, which is available to authorized users.

E. Muszyńska $(\bowtie)$

Department of Botany, Warsaw University of Life Sciences (SGGW), Faculty of Agriculture and Biology, Nowoursynowska 159, Building 37, 02-776 Warsaw, Poland

e-mail: ewa_muszynska@sggw.pl

E. Hanus-Fajerska · A. Koźmińska

Faculty of Biotechnology and Horticulture, Institute of Plant Biology and Biotechnology, Unit of Botany and Plant Physiology, University of Agriculture, al. 29-Listopada 54, 31-425 Krakow, Poland and contributed to shoot wither. On the contrary, the proliferative shoot cultures were established on media containing $\mathrm{Cd}$ ions and the multiplication coefficients and shoot length increased on all media enriched with $\mathrm{CdCl}_{2}$. Chlorophylls and carotenoid contents were negatively affected by application of $5.0 \mu \mathrm{M}$ of cadmium; nevertheless, in shoots treated with $2.5 \mu \mathrm{M} \mathrm{CdCl}_{2}$, increased accumulation of photosynthetic pigments occurred and their amount was similar to untreated culture. Adaptation to $\mathrm{Cd}$ was associated with stimulation of phenolic compound synthesis. Hence, we have reported on unambiguous positive result of in vitro selection procedure to obtain vigorous shoot culture tolerant to cadmium.

Keywords Cadmium · Facultative metallophyte · In vitro selection $\cdot$ Lead $\cdot$ Medium supplementation

\section{Introduction}

For years, metallophytes of both natural and humaninfluenced metalliferous soils have focused considerable attention due to their unique appearance and ability to colonize extremely harsh habitats. Through evolution, the plants occurring on metalliferous habitats have developed a range of intriguing adaptive traits, demonstrated as unique morphological, behavioral, and physiological alterations that enable them to avoid or tolerate metal toxicity (Gołębiewski et al. 2014; Woch et al. 2016; Wójcik et al. 2017). Thus, metallophytes possess mechanisms responsible for plant cell protection from 
excess amount of metallic ions which may get into the protoplast as well as for their detoxification inside the cell by chelation, vacuolar sequestration, or exclusion from the symplast. Such mechanisms have resulted in highly specialized plants able to (hyper) accumulate or avoid metals from the shoots. These unique taxa, mainly species or subspecies have the great potential to be applied during rehabilitation schemes and/or phytoremediation of metal-polluted sites. Moreover, metal-rich plant biomass can be used as a "bio-ore" for recovery of precious metallic elements (phytomining, agromining), as an eco-catalysts for various chemical transformations or as a natural source of micronutrients that are essential for human diet (biofortification). Undoubtedly, there is an urgent need of protection of metalliferous sites and conservation of metallophyte biodiversity (Muszyńska et al. 2017; Muszyńska and Hanus-Fajerska 2017; Wójcik et al. 2017). During the last several years, in vitro culture techniques have been extensively developed and applied to support plant conservation (Engelman 2011; Kikowska et al. 2014; Alfonso et al. 2017; Boisson et al. 2017). The elaboration of effective protocols which allow to micropropagate of valuable plant species is also prerequisite for genetic transformation procedures that may improve their potential for environmental remediation (Doran 2009; da Conceição Gomes et al. 2016; Das et al. 2016). A feasible and rather costeffective alternative to genetic manipulation could be the acquisition of resistant plant material by in vitro selection (Wiszniewska et al. 2015; Kumar et al. 2016). This approach can operate under wholly controlled conditions, with limited space, and can considerably shorten the time needed for searching of desirable traits under given selection pressure with minimal environmental interaction (Ribalta et al. 2014). Thus, it can complement the usual field selection. Plants tolerant to various abiotic and biotic stresses might be obtained by applying the chosen cultivation protocol with appropriate selecting agents such as $\mathrm{NaCl}$ (for generating salt tolerance), PEG or mannitol (for drought tolerance), trace metals/metalloids (for heavy metals/metalloids tolerance), pathogen culture filtrate, phytotoxin, or pathogen itself (for disease resistance) (Hanus-Fajerska et al. 2000; Ashrafzzadeh and Leung 2015; Wiszniewska et al. 2015, 2017; El-Minisy et al. 2016; Kumar et al. 2016). Only the explants capable of long run surviving in the presence of proper agent are selected due to the induction of genetic variation among cells, tissues, and/ or organs in cultured and regenerated plants (Rai et al. 2001; Sakhanokho and Kelley 2009). In vitro selection might thus efficiently save the time required for developing abiotic stress tolerant or disease resistant line of important plant species but genetic stability of the selected trait should be confirmed, and selected variants should be finally field-tested. Although there are genetic, biochemical, and physiological constraints in obtaining in vitro stress-tolerant plants this technique has been successfully used to produce stress-tolerant plants from several genus (Mohamed et al. 2000; Wiszniewska et al. 2015; Kumar et al. 2016). Therefore, there is not much literature data on tissue culture of metallophytes for this purpose (Zheng et al. 2007; Wiszniewska et al. 2015; Muszyńska et al. 2017).

Gypsophila fastigiata (Caryophyllaceae) spontaneously occurs on the $\mathrm{Zn}-\mathrm{Pb}$ waste heaps located in the south-eastern part of the Ślasko-Krakowska Upland, Poland (Muszyńska et al. 2015; Woch et al. 2016). As local ecotype adapted to unfavorable conditions of toxic heavy metals' level, nutrient deficiency, high insolation, strong wind, drought, unfavorable $\mathrm{pH}$ value, it is a unique plant species. The ex situ conservation might contribute to the maintenance of genetic diversity of the genus. Therefore, in the present experiment, we proposed to elaborate the multiplication protocol of $G$. fastigiata that allows the preservation of these metal-tolerant species. We hypothesized that the calamine ecotype of $G$. fastigiata would require the addition of lead or cadmium ions to the culture medium. Thus, simultaneously, we could undertake the selection of lines tolerant to those heavy metals. Such approach of metallophytes selection by in vitro methods incorporated with molecular and functional genomics can provide a new opportunity to improve stress tolerance in plants relevant to environmental sustainability.

\section{Materials and Methods}

\subsection{Source of Plant Material}

The donor material to initiate in vitro culture was seed samples taken from G. fastigiata L. specimens (Caryophyllaceae Juss.) belonging to the calamine population which spontaneously appears on an old waste heap obtained after $\mathrm{Zn}-\mathrm{Pb}$ ore mining and processing in 
the Olkusz Ore-bearing region (south-eastern part of the Ślasko-Krakowska Upland, Poland). The seeds were immersed in $70 \%(v / v)$ ethanol for $1 \mathrm{~min}$ and surface decontaminated with $0.05 \%$ mercuric chloride for $4 \mathrm{~min}$. After five washes with sterile distilled water, they were put onto MS medium (Murashige and Skoog 1962) without plant growth regulators. Shoot tips of aseptically obtained seedlings were used as primary explants.

\subsection{Elaboration of Propagation Protocol}

\subsubsection{Establishment of Proliferating Shoot Culture}

Seedling shoots deprived of roots were placed onto MS medium supplemented with $20 \mathrm{~g} \mathrm{~L}^{-1}$ sucrose, $0.65 \mathrm{mg} \mathrm{L}^{-1}$ calcium gluconate, $0.5 \mathrm{~g} \mathrm{~L}^{-1}$ polyvinylpyrrolidone (PVP), and $0.5 \mathrm{~g} \mathrm{~L}^{-1} 2-\mathrm{N}$-morpholinoethanesulfonic acid (MES). The following composition of plant growth regulators added to MS medium were tested:

1. $\quad 1.0 \mathrm{mg} \mathrm{L}^{-1} \mathrm{BAP}+0.2 \mathrm{mg} \mathrm{L}^{-1} \mathrm{NAA}$ (described further as $D 1$ )

2. $1.0 \mathrm{mg} \mathrm{L}^{-1} 2 \mathrm{iP}+0.2 \mathrm{mg} \mathrm{L}^{-1} \mathrm{NAA}$ (described further as $D 2$ )

3. $1.0 \mathrm{mg} \mathrm{L}^{-1} \mathrm{BAP}+0.2 \mathrm{mg} \mathrm{L}{ }^{-1}$ IAA (described further as $D 3$ )

4. $1.0 \mathrm{mg} \mathrm{L}^{-1} 2 \mathrm{iP}+0.2 \mathrm{mg} \mathrm{L}^{-1} \mathrm{IAA}$ (described further as $D 4$ )

The media were solidified with $0.8 \%$ Difco Bacto agar, and their $\mathrm{pH}$ was adjusted to 5.8 before autoclaving. Five explants per $100-\mathrm{mL}$ Erlenmeyer flask were explanted on the respective media. Six flasks per each treatment were used, which correspond to 30 explants per 1 replication. Subcultures were done with 8 -week intervals. After 16 weeks, the shoots were counted and micropropagation coefficient (MC) was calculated using the following formula, which was previously successfully used by Muszyńska and Hanus-Fajerska (2017) for another taxonomically related species belonging to Caryophyllaceae:

$\mathrm{MC}=$ number of induced adventitious shoots/total number of explants

Shoots (as well as roots if developed) were measured and weighted. For dry matter determination, the plant material was oven-dried in $105^{\circ} \mathrm{C}$ for $24 \mathrm{~h}$ and weighted afterward.

\subsubsection{The Rooting Stage}

In vitro raised shoots cut under laminar flow chamber were used to investigate the rooting efficiency. The effect of modified MS medium differing in the content of macro- and microelements (by supplementation with $20 \mathrm{~g} \mathrm{~L}^{-1}$ sucrose, $0.65 \mathrm{~g} \mathrm{~L}^{-1}$ calcium gluconate, $0.5 \mathrm{~g} \mathrm{~L}^{-1}$ PVP, $0.5 \mathrm{~g} \mathrm{~L}^{-1} \mathrm{MES}$ ), and with addition of $1 \mathrm{mg} \mathrm{L}^{-1}$ IAA, on the rooting stage was verified (described further as MSR). The variant of the rooting medium contained all the same ingredients but the macro- and micronutrients were reduced by half (described further as $1 / 2 \mathrm{MSR}$ ). The media were solidified with $0.8 \%$ Difco Bacto agar, and $\mathrm{pH}$ was adjusted to 5.8 before autoclaving. Five shoots, about $15-20 \mathrm{~mm}$ long, per $100-\mathrm{mL}$ Erlenmeyer flask were explanted on the respective rooting media. The assessment of rooting dynamics was conducted during 8 weeks. Counting of adventitious roots was carried out every 4 days during this period.

\subsubsection{Acclimatization of Microcuttings}

Thirty-five microcuttings rooted on 1/2 MSR medium were transferred to ceramic pots in diameter of $90 \mathrm{~mm}$ filled with sterile mixture of perlite and horticultural soil in 1:1 ratio. During the first 2 weeks, plantlets were protected with transparent containers in order to provide optimum humidity. Afterwards, they were transferred to the greenhouse with a temperature of $18-20{ }^{\circ} \mathrm{C}$. The percentage of survived specimens was calculated after 8 weeks of ex vitro planting, and at that time, they were transplanted to bigger pots (100 mm of diameter) containing a mixture of perlite, horticultural soil, and calamine substratum on which population of examined plant species was grown in natural conditions $(1: 1: 3 v / v)$. The chemical properties of calamine substratum were previously characterized in details and described by Muszyńska et al. (2017).

\subsubsection{In Vitro Selection and Evaluation of Plant Growth Parameters}

The selection was conducted using the medium supplemented with different combination of lead nitrate or cadmium chloride. The following treatments were evaluated: $0.1,0.5$, and $1.0 \mathrm{mM} \mathrm{Pb}\left(\mathrm{NO}_{3}\right)_{2}$ as well as 0.5 , 2.5 , and $5.0 \mu \mathrm{M} \mathrm{CdCl}$. Five explants (microcuttings) per $100-\mathrm{mL}$ Erlenmeyer flask were explanted on the 
respective media. Six flasks per each treatment were used, which correspond to 30 explants per 1 replication. Subcultures were done with 8-week intervals. After 24 weeks of heavy metals treatment, the obtained cultures were measured and weighted similarly to the previous step related to the optimization of proliferating shoot protocol. Into this step of experimental scheme $D 4$ medium was applied. The main measure of medium effectiveness was the efficiency of multiplication and fitness of prolonged shoot culture.

\subsubsection{Biochemical Analysis}

At the end of heavy metal treatment, the physiological condition was determined using UV/VIS spectrophotometry (Hitachi U-2900 spectrophotometer, Japan). For all biochemical analyses, three randomly chosen shoot samples (each of $0.1 \mathrm{~g}$ ) per treatment were used. The content of photosynthetic pigments in obtained plant material was determined according to Wellburn (1994). The samples were ground with $80 \%$ acetone with the addition of $\mathrm{CaCO}_{3}$. The obtained extract was centrifuged for $15 \mathrm{~min}$ at $4800 \mathrm{rpm}$, and supernatant was filled up to a volume of $10 \mathrm{~mL}$ with $80 \%$ acetone. The chlorophyll $a$, chlorophyll $b$, and carotenoid contents were estimated by measurement of the absorbance at 470,646 , and $663 \mathrm{~nm}$, respectively. The concentration of phenolic compounds was determined according to Fukumoto and Mazza (2000). The samples were homogenized with $10 \mathrm{~mL}$ of $80 \%$ methanol and centrifuged for $15 \mathrm{~min}$ at $4800 \mathrm{rpm}$. The supernatant was mixed with $0.1 \% \mathrm{HCl}$ (in $96 \%$ ethanol) and $2 \% \mathrm{HCl}$ (in water), and after $15 \mathrm{~min}$, the absorbance at 280 , 320,360 , and $520 \mathrm{~nm}$ was read for total phenols, phenolic acids, flavonols, and anthocyanins, respectively. Chlorogenic acid (sum of phenols) caffeic acid (phenylpropanoids), quercetin (flavonoids), and cyanidin (anthocyanins) were used to determine the particular group of phenols.

\subsection{Experimental Design and Statistical Analysis}

In total, the experiment lasted 48 weeks with an 8 -week subcultures. Therein, the optimization of multiplication protocol was proceeded during 16 weeks and the rooting stage lasted 8 weeks, while the heavy metal treatment was performed during the subsequent 24 weeks. The experiment was repeated independently three times (three replications). Microcuttings were randomly assigned to treatments. All media were prepared directly before the culture establishment and autoclaved at $121{ }^{\circ} \mathrm{C}, 0.1 \mathrm{MPa}$ for $20 \mathrm{~min}$. The cultures were maintained in a growth chamber at $24{ }^{\circ} \mathrm{C}$ day $/ 20^{\circ} \mathrm{C}$ night, under 16-h photoperiod (photon flux density $80 \mu \mathrm{mol} \mathrm{m} \mathrm{s}^{-1}$, Philips TL 33).

The data were subjected to ANOVA analysis (STATISTICA 12.5, StatSoft, Tulsa, OK, USA), and a post hoc Fisher's test was performed to determine differences between treatments at $P<0.05$. Some biometrical parameters were evaluated with Pearson's linear correlation, and correlation coefficients were estimated.

\section{Results}

\subsection{Elaboration of Propagation Protocol}

Proliferative shoot cultures were obtained regardless of tested plant growth regulators, and micropropagation coefficient of $G$. fastigiata ranged between 3.5 and 6.5 (Table 1; Fig. 1a-c). The greatest efficiency of shoot multiplication was observed on $D 4$ medium supplemented with $1.0 \mathrm{mg} \mathrm{L}^{-1} 2 \mathrm{iP}$ and $0.2 \mathrm{mg} \mathrm{L}^{-1}$ IAA $(\mathrm{MC}=6.5)$. In comparison with this treatment, statistically significant reduction in the number of regenerated shoots from a single explant was noticed on cultures treated with $1.0 \mathrm{mg} \mathrm{L}^{-1} \mathrm{BAP}$ and various auxins, i.e., $0.2 \mathrm{mg} \mathrm{L}^{-1} \mathrm{NAA}$ (D1 medium) or $0.2 \mathrm{mg} \mathrm{L}^{-1}$ IAA (D3 medium), and amounted $\mathrm{MC}=3.8$ and $\mathrm{MC}=3.5$, respectively. Moreover, the shoots regenerated on $D 4$ medium was almost three times longer than the shortest ones from D1 medium, and their length reached the highest value, i.e. $27 \mathrm{~mm}$. The differences between treatments in the shoot number and their length resulted in significant variation in shoots fresh matter content. The lowest value, which was about $74 \%$ of the highest one obtained on $D 4$ medium (approx. $1 \mathrm{~g}$ ), was noted for shoots proliferated on $D 1$ and $D 3$ medium (Table 1). Although on $D 2$ medium the values of all examined biometric parameters were found to be intermediate, the regenerated shoots were thick, sometimes vitreous and curled (Fig. 1a).

The applied combination of plant growth regulators did not stimulate the spontaneous regeneration of adventitious roots (Table 1 ). The exception was $D 4$ medium enriched with $1.0 \mathrm{mg} \mathrm{L}^{-1} 2 \mathrm{iP}$ and $0.2 \mathrm{mg} \mathrm{L}^{-1}$ IAA on which rhizogenesis was noticed. Nevertheless, the values of examined rooting characteristic, such as roots 
Table 1 The influence of different media composition on G. fastigiata growth parameters after 16 weeks of in vitro cultivation

\begin{tabular}{|c|c|c|c|c|c|c|c|c|}
\hline $\begin{array}{l}\text { Culture } \\
\text { medium }\end{array}$ & $\begin{array}{l}\text { Multiplication } \\
\text { coefficient }\end{array}$ & $\begin{array}{l}\text { Shoot } \\
\text { length } \\
(\mathrm{mm})\end{array}$ & $\begin{array}{l}\text { Shoot fresh } \\
\text { weight }(\mathrm{g})\end{array}$ & $\begin{array}{l}\text { Shoot dry } \\
\text { weight (\% f.w.) }\end{array}$ & $\begin{array}{l}\text { No. of roots/ } \\
\text { explant }\end{array}$ & $\begin{array}{l}\text { Root } \\
\text { length } \\
(\mathrm{mm})\end{array}$ & $\begin{array}{l}\text { Root fresh } \\
\text { weight (g) }\end{array}$ & $\begin{array}{l}\text { Root dry } \\
\text { weight (\% f.w.) }\end{array}$ \\
\hline D1 & $3.83 \mathrm{bc}^{\mathrm{a}}$ & $9.85 \mathrm{c}$ & $0.745 \mathrm{c}^{\mathrm{a}}$ & $8.57 \mathrm{~b}$ & 0.00 & 0.00 & 0.000 & 0.00 \\
\hline D2 & $5.29 \mathrm{ab}$ & $14.35 \mathrm{~b}$ & $0.838 \mathrm{~b}$ & $7.06 \mathrm{c}$ & 0.00 & 0.00 & 0.000 & 0.00 \\
\hline D3 & $3.50 \mathrm{bc}$ & $12.53 \mathrm{bc}$ & $0.743 \mathrm{c}$ & $10.13 \mathrm{a}$ & 0.00 & 0.00 & 0.000 & 0.00 \\
\hline D4 & $6.50 \mathrm{a}$ & $27.10 \mathrm{a}$ & $1.045 \mathrm{a}$ & $7.11 \mathrm{c}$ & 2.71 & 48.96 & 0.102 & 8.16 \\
\hline
\end{tabular}

Means indicated by the same letter within the columns do not significantly differ at $P<0.05$ according to Fisher's test

${ }^{\text {a }}$ Values are means of three replicates

number/explant, their length, as well as fresh and dry matter were not very satisfactory. For this reason, in the elaborated clonal propagation separate rooting stage was indeed necessary. The rate of root regeneration and their number per explant proved to be variable depending on particular medium treatment (Fig. 2). Although the first adventitious roots were noticed after 12 days of cultivation on MSR medium, during the first 4 weeks, the formation of new roots on applied medium was slow (average increment about 3). Moreover, in the 7th week, microplantlets in this treatment stopped producing new roots which reached the highest value equal to 28. Therefore, the microplants obtained on MSR medium were excluded from the scope of presently reported experiments. Instead, 1/2 MSR medium stimulated rhizogenesis what was manifested by the constant increase of adventitious root number, especially between 32 and 36 day of observation (increment by 12). Due to this process at the end of those experimental stage, the largest number of regenerated roots, which exceeded 40 per explant, was observed on $1 / 2 \mathrm{MSR}$ medium. This value was 1.5 times higher than the value obtained in culture from MSR medium estimated in the same time. Thus, the convenient medium for permanent increase of root regeneration in G. fastigiata proved to be $1 / 2 M S R$.

\subsection{Acclimatization of Microcuttings}

Despite the protection with transparent containers, the strong turgor loss of shoots and their dying were observed just after 4 days of ex vitro cultivation. Finally, $46 \%$ of the regenerated plants survived during the step of greenhouse cultivation, and after 8 weeks, they were transplanted to a bigger pots filled with calamine substratum (Fig. 1d). In this experimental step, survival rate reached $100 \%$ and no negative influence of calamine substratum on $G$. fastigiata growth and development was noticed (Fig. 1e).

\subsection{In Vitro Selection and Evaluation of Plant Growth Parameters}

During micropropagation step in the presence of heavy metals, the influence of lead nitrate on $G$. fastigiata growth was observed just after 3 weeks of 0.5 and $1.0 \mathrm{mM} \mathrm{Pb}^{2+}$ exposure. For these cultures, leaf necrosis and intensive anthocyanin discoloration were noticed (Fig. 1f-h). Similar symptoms of phytotoxic effects were found in cultures treated with $0.1 \mathrm{mM} \mathrm{Pb}\left(\mathrm{NO}_{3}\right)_{2}$; however, their reaction was delayed and noticeable after 8 weeks of cultivation. Finally, irrespective of the applied lead concentrations, the whole culture died. Thus, any biometric and biochemical measurements could not be performed. In the next experimental step, the reaction of shoots on the increasing concentration of cadmium chloride was investigated (Fig. 1i). After 8 weeks of cultivation, the micropropagation coefficient on medium supplemented with 0.5 and $2.5 \mu \mathrm{M} \mathrm{CdCl}_{2}$ amounted to 4 and was about $26 \%$ lower than in control culture. Moreover, the mean shoot length increased gradually with the increasing concentrations of cadmium ions from about $31 \mathrm{~mm}$ in the control treatment, through $34 \mathrm{~mm}$ in case of the lowest dose of $\mathrm{Cd}^{2+}$ to $39 \mathrm{~mm}$ in 2.5 and $5.0 \mu \mathrm{M}$ Cd treatment (Fig. 3a). In turn, after 16 weeks of culture, the lowest values of micropropagation coefficient were noticed on media enriched with 0.5 and $5.0 \mu \mathrm{M} \mathrm{Cd}^{2+}$ (average $\mathrm{MC}=$ 5.2), while the highest number of regenerated shoots was obtained on medium without the addition of cadmium ions as well as on medium containing $2.5 \mu \mathrm{M}$ $\mathrm{Cd}^{2+}(\mathrm{MC}=7.4)$ (Fig. 3b). After 16 weeks of 

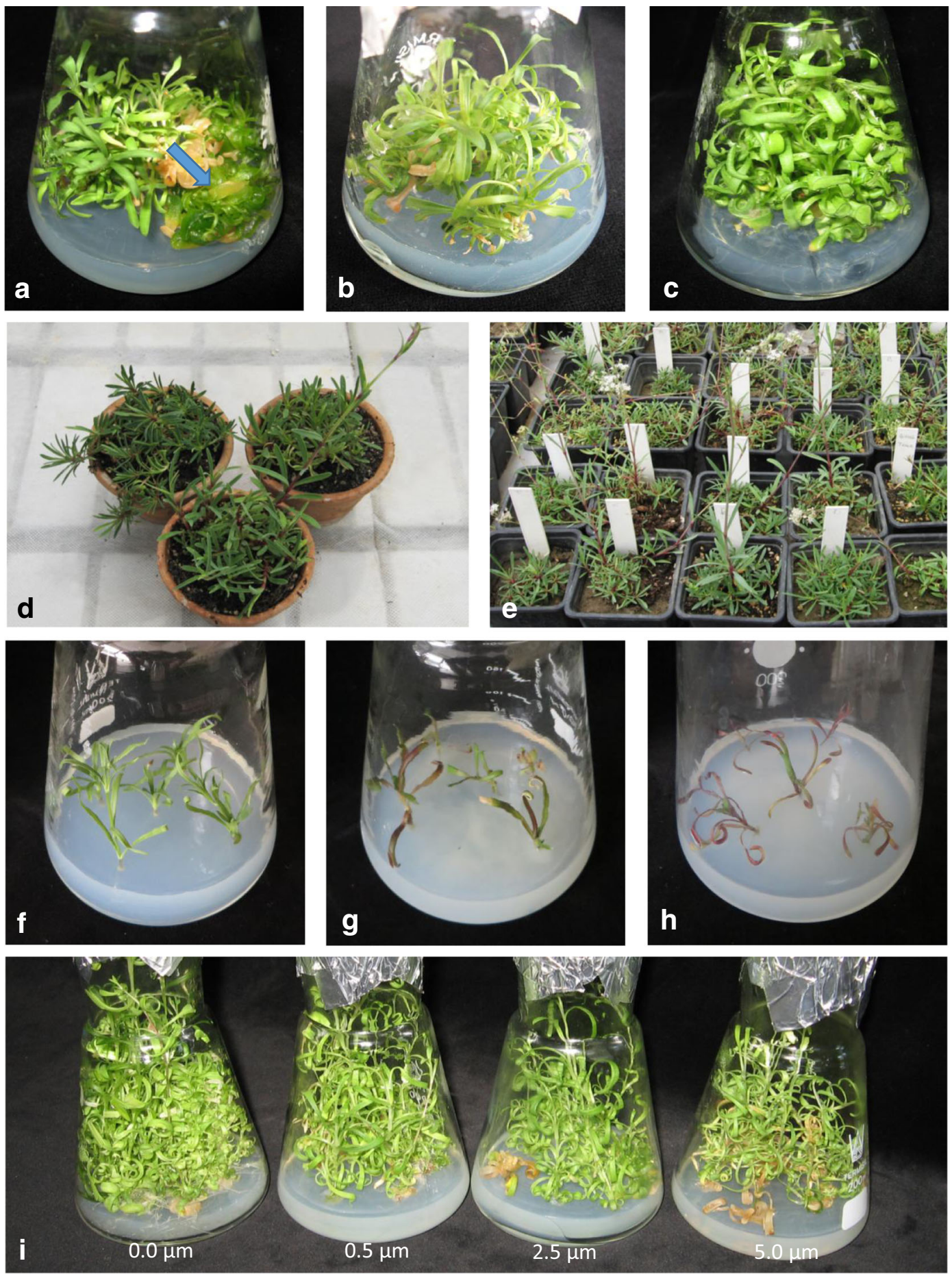

Fig. 1 The growth of $G$. fastigiata cultures on various experimental stages. a-c Proliferative shoot cultures on medium D2 (a), D3 (b), and D4 (c) during optimization of clonal propagation. d, e Acclimatized microcuttings after 8 weeks of ex vitro growth (d) and during their cultivation on calamine substratum (e). $\mathbf{f}-\mathbf{h}$ Leaves necrosis and shoots dying on medium enriched with 0.1 (f), $0.5(\mathbf{g})$, and $1.0 \mathrm{mM}$ (h) $\mathrm{Pb}\left(\mathrm{NO}_{3}\right)_{2}$. i Culture reaction on increasing concentration of $\mathrm{CdCl}_{2}$ in the growth medium 
Fig. 2 Root growth dynamics of $G$. fastigiata on media differing in the content of macro- and microelements. The following observations (I-XIV) were performed every 4 days for 8 weeks

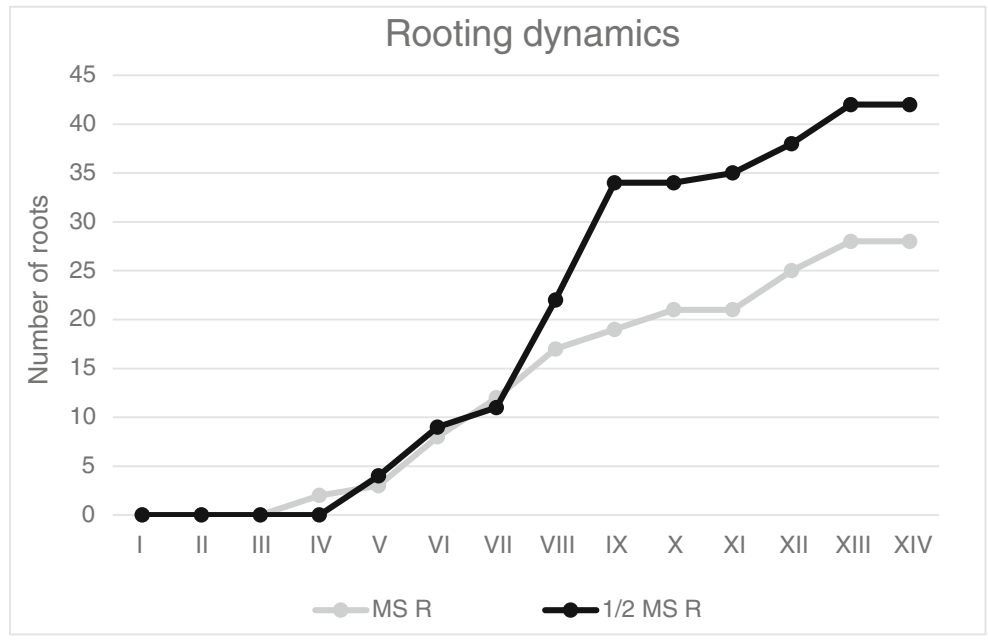

cultivation, the length of propagated shoots varied from 40 to $43 \mathrm{~mm}$. Nevertheless, these values were statistically insignificant (Fig. 3b). During the III passage, the micropropagation efficiency on Cd-supplemented media ranged from 5.8 to 7.8 (Fig. 3b), and the highest shoots were regenerated under the influence of $0.5 \mu \mathrm{M}$ $\mathrm{CdCl}_{2}$, while the lowest one was in $5.0 \mu \mathrm{M}$ Cd-treated culture (Fig. 3b). Independently on the treatment, the multiplication rate increased with cultivation time, and the largest differences in the average number of shoots regenerated from one explant between the first and the last passage were found for control and $2.5 \mu \mathrm{M} \mathrm{Cd}-$ treated culture (3.6 and 3.8, respectively) (Fig. 3a). Similarly, the shoot length changed with the lapse of $\mathrm{Cd}$ exposure, and the largest variation of this parameter was noticed in cultures growing on medium supplemented with $0.5 \mu \mathrm{M} \mathrm{CdCl}_{2}$. The obtained results indicated a significant positive correlation between the subsequent passages and micropropagation coefficient, which for shoots cultivated in the presence of 0.5 and $2.5 \mu \mathrm{M} \mathrm{CdCl} 2$ was at the moderate level of $r=0.58$, while for both untreated shoots and shoots treated with $5.0 \mathrm{CdCl}_{2}$ was about 0.35 (Fig. 3a). The weak uphill relationship of $0.37-0.41$ between the time culture and shoot length was also shown for control and $0.5 \mu \mathrm{M}$ treated cultures (suppl. data).

The highest concentration of $\mathrm{Cd}^{2+}$ significantly affected shoots fresh weight which was about $15 \%$ lower than in other treatments, and reached approximately $1.1 \mathrm{~g}$ (Table 2). On the other hand, the content of dry matter in shoots differed between treatments, and the highest amount was noted in shoots from medium with $2.5 \mathrm{CdCl}_{2}$, while the lowest one in control culture. The applied concentrations of cadmium chloride significantly influenced on rhizogenesis (Table 2). In Cd-treated cultures, the percentage of spontaneously rooted explants varied from 33 to $42 \%$ and was about two times lower than in untreated one. Additionally, the adventitious root number regenerated per one explant and root length were strongly inhibited on media containing $\mathrm{Cd}$ ions. The decrease in examined characteristics resulted in the reduction of root fresh and dry matter in comparison with their contents obtained on nonsupplemented medium.

\subsection{Biochemical Analysis}

The concentration of photosynthetic pigments in shoots cultured in the presence of $2.5 \mu \mathrm{M} \mathrm{CdCl}_{2}$ was proved to be similar to that from medium without $\mathrm{Cd}$ ions and reached about $0.50 \mathrm{mg} \mathrm{g}^{-1}$ f.w. for chlorophyll $a$, $0.14 \mathrm{mg} \mathrm{g}^{-1}$ f.w. for chlorophyll $b$, and $0.13 \mathrm{mg} \mathrm{g}^{-1}$ f.w. for carotenoids (Fig. 4). The content of both chlorophyll types, as well as carotenoids, significantly decreased in shoots obtained on medium enriched with the highest dose of cadmium ions and reached the lowest values. In turn, $0.5 \mu \mathrm{M}$ Cd-treated shoots contained intermediate pigment amount. The accumulation of all groups of phenolic compounds was significantly elevated in shoots of $2.5 \mu \mathrm{M} \mathrm{Cd}^{2+}$-treated line in comparison with other cultures (Fig. 5). Moreover, the differences in the level of phenols detected in control shoots as well as in shoots developed on media enriched with 0.5 and $5.0 \mu \mathrm{M} \mathrm{CdCl}_{2}$ were statistically insignificant and ranged from 397 to $401 \mathrm{mg}$ for total phenols, from 98 to $107 \mathrm{mg}$ 
Fig. 3 Changes in micropropagation efficiency of G. fastigiata on media supplemented with cadmium ions, evaluated after 8,16 , and 24 weeks of cultivation (I, II, III, respectively). Different letters within the following passage indicate means that are significantly different at $P<0.05$. Dots indicate statistically significant correlation between the subsequent passage and particular growth parameter

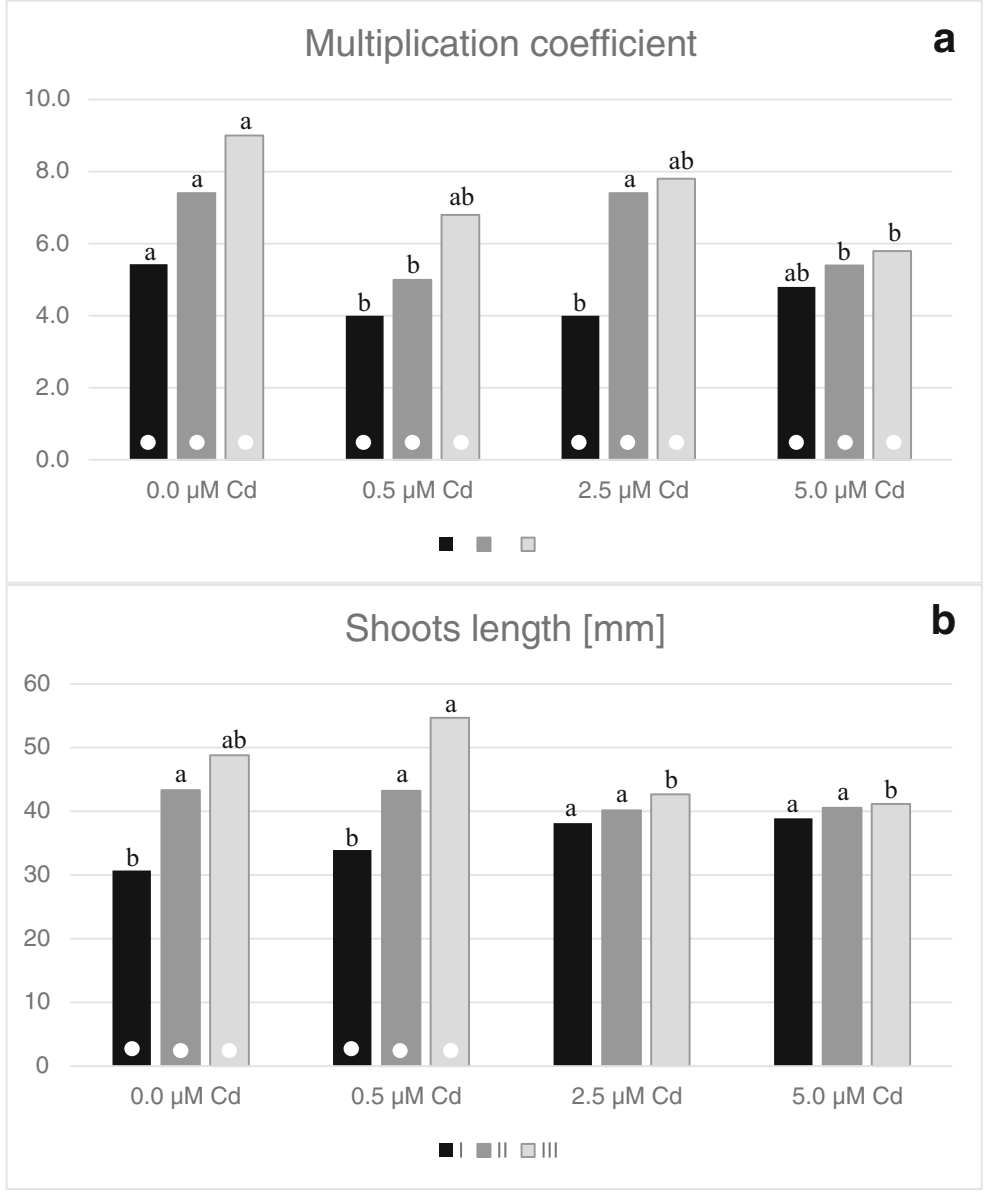

for phenylopropanoids, and from 120 to $126 \mathrm{mg} / 100 \mathrm{~g}$ f.w. for flavonols, while in shoots developed on medium enriched with $2.5 \mu \mathrm{M} \mathrm{CdCl}_{2}$, their concentrations were significantly higher and got 436, 113, and $141 \mathrm{mg} / 100 \mathrm{~g}$ f.w., respectively. The most variable group of phenols was anthocyanins. Their accumulation in shoots cultivated in the presence of $2.5 \mu \mathrm{M} \mathrm{CdCl}_{2}$ was the highest (48 mg/100 g f.w.) and reached about $40 \%$ higher value than in control shoots and culture treated with $5.0 \mu \mathrm{M}$ $\mathrm{Cd}^{2+}$.

Table 2 The fresh and dry matter content of G. fastigiata shoots as well as rhizogenesis after 24 weeks of cultivation in the presence of cadmium ions

\begin{tabular}{llllllll}
\hline $\begin{array}{l}\text { Cadmium } \\
\text { treatment }\end{array}$ & $\begin{array}{l}\text { Shoot fresh } \\
\text { weight }(\mathrm{g})\end{array}$ & $\begin{array}{l}\text { Shoot dry weight } \\
(\% \text { f.w. })\end{array}$ & $\begin{array}{l}\text { Rooted } \\
\text { shoots }(\%)\end{array}$ & $\begin{array}{l}\text { No. of roots/ } \\
\text { microplant }\end{array}$ & $\begin{array}{l}\text { Root length } \\
(\mathrm{mm})\end{array}$ & $\begin{array}{l}\text { Root fresh } \\
\text { weight (g) }\end{array}$ & $\begin{array}{l}\text { Root dry weight } \\
(\% \text { f.w. })\end{array}$ \\
\hline $\begin{array}{c}0.0 \mu \mathrm{M} \\
\mathrm{CdCl}_{2}\end{array}$ & $1.34 \mathrm{a}^{\mathrm{a}}$ & $9.38 \mathrm{~b}$ & $85.71 \mathrm{a}$ & $12.40 \mathrm{a}$ & $25.92 \mathrm{a}$ & $0.414 \mathrm{a}$ & $14.42 \mathrm{a}$ \\
$\begin{array}{c}0.5 \mu \mathrm{M} \\
\mathrm{CdCl} l_{2}\end{array}$ & $1.33 \mathrm{a}$ & $9.95 \mathrm{~b}$ & $42.85 \mathrm{~b}$ & $6.80 \mathrm{~b}$ & $19.20 \mathrm{~b}$ & $0.018 \mathrm{~b}$ & $7.38 \mathrm{c}$ \\
$\begin{array}{c}2.5 \mu \mathrm{M} \\
\mathrm{CdCl}\end{array}$ & $1.32 \mathrm{a}$ & $11.15 \mathrm{a}$ & $33.50 \mathrm{c}$ & $6.00 \mathrm{~b}$ & $17.64 \mathrm{~b}$ & $0.031 \mathrm{~b}$ & $9.62 \mathrm{~b}$ \\
$\begin{array}{c}5.0 \mu \mathrm{M} \\
\mathrm{CdCl}\end{array}$ & $1.16 \mathrm{~b}$ & $10.26 \mathrm{ab}$ & 0.00 & 0.00 & 0.00 & 0.000 & 0.00 \\
\hline
\end{tabular}

Means indicated by the same letter within the columns do not significantly differ at $P<0.05$ according to Fisher's test

${ }^{a}$ Values are means of three replicates 
Fig. 4 The content of photosynthetic pigments: chlorophyll $a$, chlorophyll $b$, and carotenoids in shoots of G. fastigiata cultured in the presence of various doses of cadmium chloride. Different letters indicate means that are significantly different at $P<0.05$

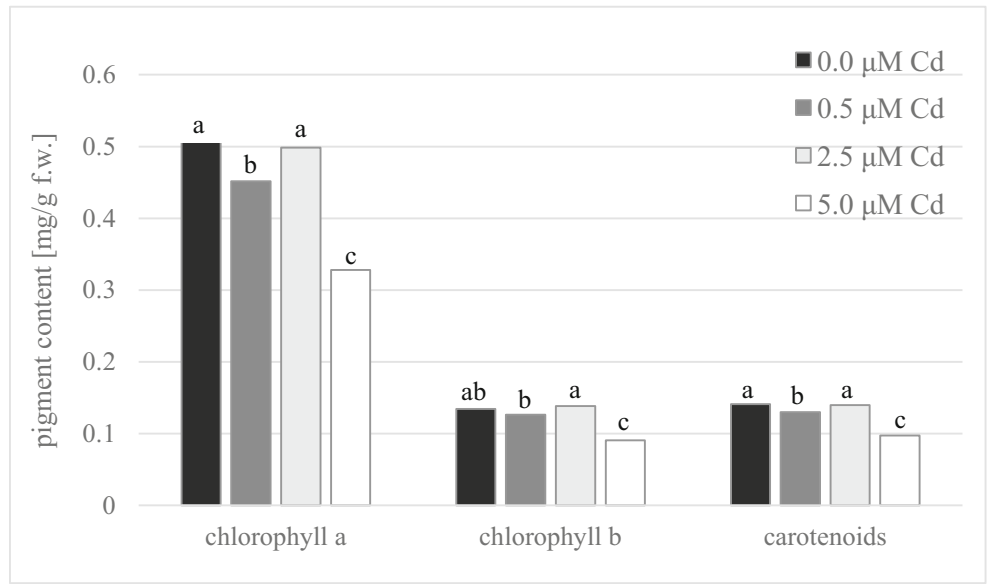

\section{Discussion}

In our previous studies, it was ascertained that among the species considered as a potential candidates for phytoremediation techniques, such calamine ecotype of $G$. fastigiata is an interesting object since it is a pioneer plant occurring spontaneously on $\mathrm{Zn}-\mathrm{Pb}$ postflotation waste tailings located in Olkusz Ore-bearing Region, and its importance for the reclamation of such deposits has been demonstrated in the field experiment (Muszyńska et al. 2015). In the present work, the tissue culture system competent to regenerate large amount of uniform plant material ready to be applied on heavy metal-polluted areas was elaborated. To our knowledge, it is the first report on in vitro propagation of $G$. fastigiata calamine ecotype and one of the few reports relating to the use of these techniques for multiplication of facultative metallophytes (Bidwell et al. 2001; Jack et al. 2005; Zheng et al. 2007; Muszyńska and
Hanus-Fajerska 2017). In such experiments using of seeds collected from natural habitats to initiate in vitro culture is a common practice and was previously reported for others metallophytes like Alyssum corsicum (Babaoğlu Aydaş et al. 2013), Plantago algarbiensis and P. almogravensis (Gonçalves et al. 2009), or Biscutella laevigata (Hanus-Fajerska et al. 2012). Taking into account the culture condition optimized for economically important Gypsophila genus, various supplementation of MS medium were tested to elaborate the optimal medium composition for $G$. fastigiata calamine ecotype. In the study conducted by Zdraveva et al. (2015), it was found that the addition of IAA to growth medium was the most effective for secondary metabolite production of pharmaceutical importance in G. trichotomas, G. altissima, and G. paniculata shoot and callus cultures. In turn, according to the protocol proposed by Han et al. (1991), the use of MS medium containing BAP (2.0 $\left.\mathrm{mg} \mathrm{L}^{-1}\right)$ and NAA $\left(0.05 \mathrm{mg} \mathrm{L}^{-1}\right)$
Fig. 5 The concentration of phenolic compound in G. fastigiata shoots developed on media containing various doses of cadmium chloride. Different letters indicate means that are significantly different at $P<0.05$

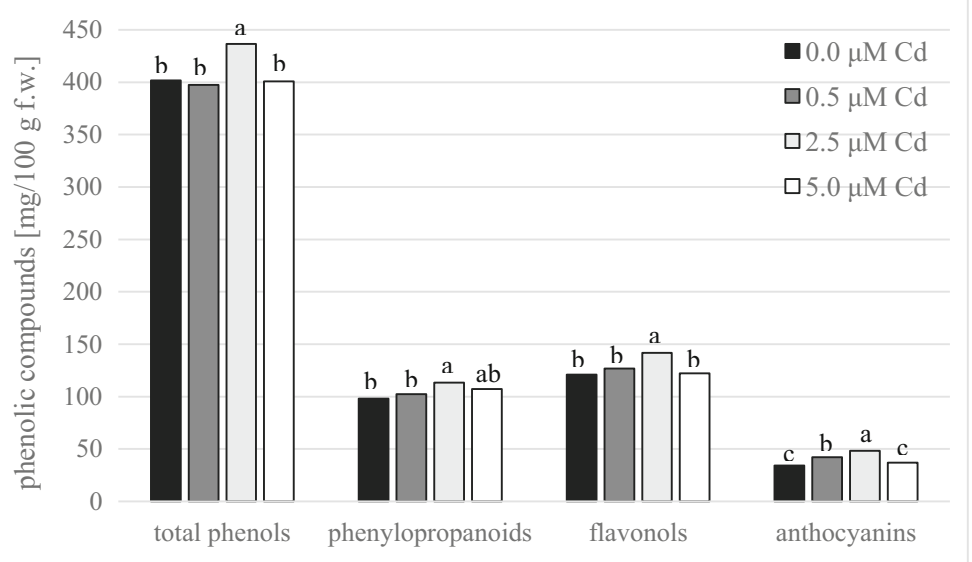


for establishment of shoot cultures of G. paniculata gave the best results. Likewise, Lee and Bae (1999) reported that the same cytokinin, but applied in lower concentrations ( $\left.0.2 \mathrm{mg} \mathrm{L}^{-1} \mathrm{BAP}\right)$, in the combination with NAA $\left(0.1\right.$ or $\left.0.2 \mathrm{mg} \mathrm{L}^{-1}\right)$ were suitable for indirect regeneration of this species from apical buds. The positive effect of BAP $\left(1.0 \mathrm{mg} \mathrm{L}^{-1}\right)$ and NAA $\left(0.2 \mathrm{mg} \mathrm{L}^{-1}\right)$ on $G$. paniculata apical and axillary bud cultures was also shown in the study of Rashid et al. (2012). Although these growth regulators intensively stimulated the multiplication of G. paniculata, their application for culture of $G$. fastigiata calamine ecotype did not bring satisfactory results. In case of tested specimens, the best growth parameters were obtained on MS medium supplemented with $1.0 \mathrm{mg} \mathrm{L}^{-1} 2 \mathrm{iP}$ and $0.2 \mathrm{mg} \mathrm{L}^{-1}$ IAA. In order to initiate root regeneration, modified MS medium with reduced macro- and micronutrient by half and enriched with $1 \mathrm{mg} \mathrm{L}^{-1}$ IAA is proposed. The transfer of microplants to ex vitro condition proved to be an essential step that allowed to verify the usefulness of in vitro technique for effective propagation of tested genotype. Albeit the frequency of plants which stood the adaptation period was slightly lower than $50 \%$, all of them survived on calamine substratum. It might suggest that the optimized micropropagation scheme provides the ex situ conservation options of this valuable plant species. Moreover, from 30 of aseptic Gypsophila seedlings, it was easily obtained about 200 of plantlets in 4 months. Therefore, the described protocol allows to regenerate a large number of plant material with intention to direct introduction on areas contaminated with heavy metals.

The optimization of reliable micropropagation protocol is a prerequisite step before conducting any in vitro selection experiments. The examined doses of lead nitrate applied to the medium for clonal propagation of G. fastigiata calamine ecotype induced growth disturbances and finally contributed to shoot culture death. Similarly, Wójcik and Tukiendorf (2014) have noted that lead nitrate even at the concentration of $30 \mu \mathrm{M}$ negatively influenced on growth of another metal-tolerant species from Caryophyllaceae family, $D i$ anthus carthusianorum, and its root development was totally inhibited in the presence of $850 \mu \mathrm{M} \mathrm{Pb}\left(\mathrm{NO}_{3}\right)_{2}$. The root system plays an important role in heavy metal detoxification. Many authors have reported that the endodermis with Casparian strips and pericycle cells have specific properties enabling them to block a symplastic transport of water and ions, and thus constitute a significant barrier to heavy metal translocation to aboveground parts of plant (Załęcka and Wierzbicka 2002; Baranowska-Morek and Wierzbicka 2004; Fernández et al. 2014; Wójcik and Tukiendorf 2014). In the present study, regardless of applied lead concentration, the regeneration of roots in $G$. fastigiata specimens was not observed. Probably, toxic ions could easily penetrate to the shoots without necessity to overcome root barrier what adversely affected plant metabolism and resulted in shoot culture dying. Thus, there is a need to verify if in the presence of fully expanded root system the negative effects of lead on shoot growth and development would be manifested. On the contrary, the proliferative shoot cultures of G. fastigiata were established on all media containing cadmium chloride and irrespective of $\mathrm{Cd}$ treatment obtained shoots were viable, with neither chlorotic, nor necrotic spots on leaves. What is more, the multiplication coefficients as well as shoot length increased on all tested media, suggesting that plants growth was not inhibited by cadmium. In order to better understand the mechanism of cadmium tolerance, several biochemical analyses were performed. The analysis of photosynthetic pigment content considered as an important indicator of heavy metals stress was significantly higher in shoots treated with $2.5 \mu \mathrm{M} \mathrm{CdCl}_{2}$ in comparison with other treatments and similar to control one. Other studies have also reported that chlorophyll level in leaves of tolerant plants does not change or ever increases in the presence of heavy metals (Burzyński and Buczek 1994; Dezhban et al. 2015). Taking into account fact that cadmium ions can negatively influence on plant organisms, the results of our study insinuate that selected line of $G$. fastigiata tolerant to $\mathrm{Cd}$ ions was obtained. Adaptation to $\mathrm{Cd}$ could be attributed to enhanced synthesis of phenolic compounds. These diverse secondary metabolites are involved in antioxidative defense systems that can protect cells from oxidative damage and scavenge harmful reactive oxygen species (ROS) commonly generated in the presence of elevated concentration of metallic elements (Lavid 2001a; Sharma et al. 2012; Wiszniewska et al. 2017). Moreover, phenolic compounds possess high ability to chelate metal ions and therefore participate in maintenance of homeostasis under heavy metal stress (Lavid et al. 2001b; Michalak 2006). In our study, the highest accumulation of all groups of phenols was observed in the best growing shoots cultivated on medium containing $2.5 \mu \mathrm{M} \mathrm{CdCl}_{2}$. Thus, one of the possible defense mechanism against cadmium stress in 
G. fastigiata calamine ecotype might be associated with enhanced accumulation of phenylopropanoinds. They are involved in lignin synthesis and its deposition within the cell walls what enable the formation of thicker and more effective mechanical barrier against the penetration of heavy metal ions inside the cell (Michalak 2006; Maestri et al. 2010). Such increase in lignin content correlated with the increase activity of phenylalanine ammonia-lyase activity (PAL, syn. EC); a key enzyme in phenylopranoid metabolism was observed in roots of Glycine max exposed to cadmium and lead (PawlakSprada et al. 2011) or in Matricaria chamomilla under the influence of cadmium and zinc (Kováčik and Klejdus 2008). In turn, flavonols and anthocyanins, classified as flavonoids, are able to stabilize cell membranes by binding to their phospholipids and thus decreasing membrane fluidity (Michalak 2006; Karuppanapandian et al. 2011; Biesiada and Tomczak 2012). According to Verstraeten et al. (2003) and Arora et al. (2000), such membrane modification might hinder the diffusion of free radicals what reduce membrane damage resulted from lipid peroxidation. Thus, it is highly probable that the mechanism of heavy metal detoxification in selected Cd-tolerant line of G. fastigiata is based on the existence of extracellular barriers restricted ions penetration into the cytoplasm. In the course of present experiment, such strategy of metal detoxification could not prevent entering of $\mathrm{Pb}$ ions. The lead is usually excluded in roots, and obtained shoots deprived roots could not activate this defensive mechanism. As a result, they were directly exposed to highly elevated, phytotoxic levels of this element. Moreover, the applied doses of lead nitrate were very high and several times exceeded the concentration of soluble form of this element identified in the calamine substrate (Muszyńska et al. 2013, 2017). The above mentioned issues could have a significant impact on obtained results. Therefore, the restoration potential of $G$. fastigiata should be confirmed in the field experiment.

To conclude, in the present study, the efficient protocol of clonal propagation under in vitro conditions of valuable $G$. fastigiata population has been described for the first time. It is perennial herb with a deep root system which grows in the dry grassland deficient in nutrients. These features make $G$. fastigiata a potential candidate for application in rehabilitation schemes and also in management of not reclaimed wastes created as a result of $\mathrm{Zn}-\mathrm{Pb}$ ore processing. Therefore, the experiments with the use of tissue culture techniques, which allow to obtain a great deal of regenerants with potential to stabilize toxic metallicolous wastes, are worth to be undertaken. Our study demonstrated that the in vitro derived plants are able to survive and develop on calamine substrate. Interestingly, the addition of lead nitrate to the propagation medium resulted in culture growth disturbances probably due to the lack of spontaneous rhizogenesis during presented experimental set. Thus, future research should focus on the role of root system in defense mechanism against $\mathrm{Pb}$ toxicity in tested species. On the contrary, it was found that cadmium supplementation might significantly increase multiplication efficiency and physiological condition of cultivated microplantlets. The strategy of $G$. fastigiata survival in the contaminated medium based on enhanced accumulation of phenolic compounds. The highest concentration of these secondary metabolites was observed in the best growing shoots cultivated on medium containing $2.5 \mu \mathrm{M} \mathrm{CdCl}_{2}$. It may implicate that we have obtained line tolerant to cadmium. However, future investigation into its exploitation in the revitalization of urban areas would be valuable.

Acknowledgements This research was supported by the Ministry of Science and Higher Education of the Republic of Poland granted to the University of Agriculture in Krakow in the form of DS 3500 .

\section{Compliance with Ethical Standards}

Conflict of Interest The authors declare that they have no conflict of interest.

Ethical Approval This article does not contain any studies with human participants or animals performed by any of the authors.

Open Access This article is distributed under the terms of the Creative Commons Attribution 4.0 International License (http:// creativecommons.org/licenses/by/4.0/), which permits unrestricted use, distribution, and reproduction in any medium, provided you give appropriate credit to the original author(s) and the source, provide a link to the Creative Commons license, and indicate if changes were made.

\section{References}

Alfonso, D., Citatelli, A., Guarino, F., Rodriguez, D., \& Castiglione, S. (2017). In vitro propagation of Leucocroton havanensis Borhidi (Euphorbiaceae): A rare serpentineendemic species of Cuba. Plant Biosystems-An 
International Journal Dealing With all Aspects of Plant Biology. https://doi.org/10.1080/11263504.1311961

Arora, A., Byrem, T. M., Nair, M. G., \& Strasburg, G. M. (2000). Modulation of liposomal membranes fluidity by flavonoids and isoflavonoids. Archives of Biochemistry and Biophysics, 373, 102-109.

Ashrafzzadeh, S., \& Leung, D. M. V. (2015). In vitro breeding of heavy metal-resistant plants: A review. Horticulture, Environment and Biotechnology, 56(2), 131-136.

Babaoğlu Aydaş, S. S., Açik, L., Leduc, D., Adigüzel, N., Ellialtioğlu, S. S., Suludere, Z., \& Kadioğlu, Y. K. (2013). Localization and distribution of nickel and other elements in in-vitro grown Alyssum corsicum exhibiting morphological changes in trichomes: Initial insights into molecular mechanisms of nickel hyperaccumulation. Turkish Journal of Botany, 37, 1115-1124.

Baranowska-Morek, A., \& Wierzbicka, M. (2004). Localization of lead in root tip of Dianthus carthusianorum. Acta Biologica Cracoviensia Series Botanica, 46, 45-56.

Bidwell, S. D., Pederick, J. W., Somer-Knudsen, J., \& Woodrow, J. E. (2001). Micropropagation of the nickel hyperaccumulator, Hybanthus floribundus (family Violaceae). Plant Cell Tissue and Organ Cultures, 67, 88-92.

Biesiada, A., \& Tomczak, A. (2012). Biotic and abiotic factors affecting the content of the chosen antioxidant compounds in vegetables. Vegetable Crops Research Bulletin, 76, 55-78.

Boisson, S., Faucon, M. P., Le Stradic, S., Lange, B., Verbruggen, N., Garin, O., Wetshy, A. T., Séleck, M., Kalengo, W. M., Schutcha, M. N., \& Mahy, G. (2017). Specialized edaphic niches of threatened copper endemic plant species in the D.R. Congo: Implications for ex situ conservation. Plant and Soil, 413, 261-273.

Burzyński, M., \& Buczek, J. (1994). The influence of Cd, Pb, Cu and $\mathrm{Ni}$ on NO3- uptake by cucumber seedlings. II. In vivo and in vitro effects of $\mathrm{Cd}, \mathrm{Pb}, \mathrm{Cu}$ and $\mathrm{Ni}$ on the plasmalemma ATPase and oxido reductase from cucumber seedlings roots. Acta Physiologiae Plantarum, 16, 297-302.

da Conceição Gomes, M. A., Hauser-Davis, R. A., de Souza, A. N., \& Vitória, A. P. (2016). Metal phytoremediation: General strategies, genetically modified plants and applications in metal nanoparticle contamination. Ecotoxicology and Environmental Safety, 134, 133-147.

Das, N., Bhattacharya, S., \& Maiti, M. K. (2016). Enhanced cadmium accumulation and tolerance in transgenic tobacco overexpressing rice metal tolerance protein gene OsMTP1 is promising for phytoremediation. Plant Physiology and Biochemistry, 105, 279-309.

Dezhban, A., Shirvany, A., Attarod, P., Delshad, M., Matinizadeh, M., \& Khoshnevis, M. (2015). Cadmium and lead effects on chlorophyll fluorescence, chlorophyll pigments and proline of Robinia pseudoacacia. Journal of Forest Research, 26(2), 3233-3229.

Doran, P. M. (2009). Application of plant tissue cultures in phytoremediation research: Incentives and limitations. Biotechnology and Bioengineering, 103(1), 60-76.

El-Minisy, A. M., Abbas, M. S., Aly, U. I., \& El-Shabrawi, H. M. (2016). In vitro selection and characterization of salt-tolerant cell lines in cassava plant (Monihot esculenta Crantz.) International Journal of ChemTech Research, 9(5), 215-227.
Engelmann, F. (2011). Use of biotechnologies for the conservation of plant biodiversity. In Vitro Cellular \& Developmental Biology-Plant, 47, 5-16.

Fernández, R., Fernández-Fuego, D., Bertrand, A., \& González, A. (2014). Strategies for Cd accumulation in Dittrichia viscosa (L.) Greuter: Role of the cell wall, non-protein thiols and organic acids. Plant Physiology and Biochemistry, 78, 63-70.

Fukumoto, L. R., \& Mazza, G. (2000). Assessing antioxidant and prooxidant activities of phenolic compounds. Journal of Agriculture and Food Chemistry, 48, 3597-3604.

Gołębiewski, M., Deja-Sikora, E., Cichosz, M., Tretyn, A., \& Wróbel, B. (2014). 16S rDNA prosequencing analysis of bacterial community in heavy metal polluted soils. Microbiol Ecology, 67, 635-647.

Gonçalves, S., Martins, N., \& Romano, A. (2009). Micropropagation and conservation of endangered species Plantago algarbiensis and P. almogravensis. Biologia Plantarum, 53(4), 7747-7778.

Han, B. H., Paek, K. Y., \& Choi, J. K. (1991). Micropropagation of G. paniculata using shoot tip culture in vitro. Journal of Korean Society of Horticultural Science, 32(3), 394-400.

Hanus-Fajerska, E., Lech, M., Pindel, A., \& Miczyński, K. (2000). Selection for virus resistance in tomato exposed to tissue culture procedures. Acta Physiologiae Plantarum, 22(3), 31-7324.

Hanus-Fajerska, E., Wiszniewska, A., \& Muszyńska, E. (2012). In vitro multiplication and acclimatization of Biscutella laevigata (Brassicaceae) to cultivation in greenhouse conditions. Biotechnologia, 93(2), 97-101.

Jack, E., Atanosova, S., \& Verkleij, J. A. (2005). Callus induction and plant regeneration in the metallophyte Silene vulgaris (Caryophyllaceae). Plant Cell Tissue and Organ Cultures, 80, 25-31.

Karuppanapandian, T., Moon, J. C., Kim, C., Manoharan, K., \& Kim, W. (2011). Reactive oxygen species in plants: Their generation, signal transduction, and scavenging mechanisms. Australian Journal of Crop Science, 5(6), 709-725.

Kikowska, M., Thiem, B., Sliwinska, E., Pewers, M., Kowalczyk, M., Stochmal, A., \& Olesyek, W. (2014). The effect of nutritional factors and plant growth regulators on micropropagation and production of phenolic acids and saponins from plantlets and adventitious root cultures of Eryngium maritimum L. Journal of Plant Growth Regulation, 33, 809-819.

Kováčik, J., \& Klejdus, B. (2008). Dynamics of phenolic acids and lignin accumulation in metal-treated Matricaria chamomilla roots. Plant Cell Report, 27, 605-615.

Kumar, S. A., Kumari, P. H., Jawahar, G., Prashanth, S., Suravajahala, P., Katam, R., Sivan, P., Rao, K. S., Kirti, P. B., \& Kavi Kishor, P. B. (2016). Beyond just being foot soldiers - osmotin like protein (OLP) and chitinase (Chi11) genes act as sentinels to confront salt, drought, and fungal stress tolerance in tomato. Environmental and Experimental Botany, 132, 53-65.

Lavid, N., Schwartz, A., Lewinson, E., \& Tel-Or, E. (2001a). Phenols and phenol oxidases are involved in cadmium accumulation in the water plants Nymphoides peltata (Menyanthaceae) and Nymphaeae (Nymphaeaceae). Planta, 214, 189-195. 
Lavid, N., Schwartz, A., Yarden, O., \& Tel-Or, E. (2001b). The involvement of phenols and peroxidase activities in heavy metals accumulation by epidermal glands of the waterlily (Nymphaeaceae). Planta, 212, 323-331.

Lee, S. W., \& Bae, J. J. (1999). Improvement of efficiency for multiplication of vigorous seedling by shoot cultured in vitro in G. paniculata L. Korean Journal of Horticulture and Science Technology, 17, 768-769.

Maestri, H., Marmiroli, M., Visoli, G., \& Marmiroli, N. (2010). Metal tolerance and hyperaccumulation. Costs and trade-offs between traits and environment. Environmental and Experimental Botany, 68, 1-13.

Michalak, A. (2006). Phenolic compounds and their antioxidant activity in plants growing under heavy metal stress. Polish Journal of Environmental Studies, 15(4), 523-530.

Mohamed, M. A. H., Harris, P. J. C., \& Henderson, J. (2000). In vitro selection and characterization of a drought tolerant clone of Tagetes minuta. Plant Science, 159, 213-222.

Murashige, T., \& Skoog, F. (1962). A revised medium for rapid growth and bioassays with tobacco tissue culture. Physiologia Plantarum, 15, 473-479.

Muszyńska, E., \& Hanus-Fajerska, E. (2017). In vitro multiplication of Dianthus cartusianorum calamine ecotype with the aim to revegetate and stabilize of polluted wastes. Plant Cell Tissue and Organ Cultes, 128, 638-640.

Muszyńska, E., Hanus-Fajerska, E., \& Ciarkowska, K. (2013). Evaluation of seed germination ability of native calamine plant species on different substrata. Polish Journal of Environmental Studies, 22(6), 1775-1780.

Muszyńska, E., Hanus-Fajerska, E., \& Ciarkowska, K. (2015). Studies on Gypsophila fastigiata parameters verifying its suitability to reclamation of post-flotation $\mathrm{Zn}-\mathrm{Pb}$ wastes. Geology, Geophysics \& Environment, 41(1), 17-24.

Muszyńska, E., Hanus-Fajerska, E., Piwowarczyk, B., Ciarkowska, K., Czech, T., \& Augustynowicz, J. (2017). From laboratory to field studies - assessment of Biscutella laevigata suitability to biological reclamation of areas contaminated with lead and cadmium. Ecotoxicology and Environmental Safety, 142, 266-273.

Pawlak-Sprada, S., Stobiecki, M., \& Deckert, J. (2011). Activation of phenylpropanoid pathway in legume plants exposed to heavy metals. Part II. Profiling of isoflavonoids and their glycoconjugates induced in roots of lupine (Lupinus luteus) seedlings treated with cadmium and lead. Acta Biochimica Polonica, 58(2), 211-216.

Rai, M. K., Kalia, R. K., Singh, R., Gangola, M. P., \& Dhawan, A. K. (2001). Developing stress tolerant plants through in vitro selection-an overview of the recent progress. Environmental and Experimental Botany, 71(1), 81-98.

Rashid, S., Ilyas, S., Naz, S., Aslam, F., \& Ali, A. (2012). In vitro propagation of Gypsophila paniculata L. through plant tissue culture techniques. Pakistan Journal of Science, 64(1), 6-10.
Ribalta, F. M., Croser, J. S., Erskine, W., Finnegan, P. M., Lulsdorf, M. M., \& Ochatt, S. J. (2014). Antigibberelininduced reduction of internode length favors in vitro flowering and seed-set in different pea genoptypes. Biologia Plantarum, 58(1), 39-46.

Sakhanokho, H. F., \& Kelley, R. Y. (2009). Influence of salicylic acid on in vitro propagation and salt tolerance in Hibiscus acetosella and Hibiscus moscheutos (cv 'Luna Red'). African Journal of Biotechnology, 8, 1474-1481.

Sharma, P., Jha, A. B., Dubey, R. S., \& Pessarakli, M. (2012). Reactive oxygen species, oxidative damage and antioxidative defense mechanism in plants under stressful conditions. Journal of Botany. https://doi.org/10.1155/2012/217037

Verstraeten, S. V., Keen, C. L., Schmitz, H. H., Fraga, C. G., \& Oteiza, P. I. (2003). Flavan-3-ols and procyanidins protect liposomes against lipid oxidation and disruption of the bilayer structure. Free Radical Biology and Medicine, 34(1), 84 92.

Wellburn, A. R. (1994). The spectral determination of chlorophylls $\mathrm{a}$ and $\mathrm{b}$, as well as total carotenoids, using various solvents with spectrophotometers of different resolution. Journal of Plant Physiology, 144, 3013-3013.

Wiszniewska, A., Hanus-Fajerska, E., Smoleń, S., \& Muszyńska, E. (2015). In vitro selection for lead tolerance in shoot culture of Daphne species. Acta Scientiarum Polonorum Hortorum Cultus, 14(1), 129-142.

Wiszniewska, A., Muszyńska, E., Hanus-Fajerska, E., Smoleń, S., Dziurka, M., \& Dziurka, K. (2017). Organic amendments enhance $\mathrm{Pb}$ tolerance and accumulation during micropropagation of Daphne jasminea. Environmental Science and Pollution Research, 24, 2424-2432.

Woch, M. W., Kapusta, P., \& Stefanowicz, A. M. (2016). Variation on dry grassland communities along a heavy metal gradient. Ecotoxicology, 25, 80-90.

Wójcik, A., \& Tukiendorf, A. (2014). Accumulation and tolerance of lead in two contrasting ecotypes of Dianthus carthusianorum. Phytochemistry, 100, 60-65.

Wójcik, M., Gonnelli, C., Selvi, F., Dresler, S., Rostański, A., \& Vangronsveld, J. (2017). Metallophytes of serpentine and calamine soils - their unique ecophysiology and potential for phytoremediation. Advances in Botanical Research. https://doi.org/10.1016/bs.abr.2016.12.002

Załęcka, R., \& Wierzbicka, M. (2002). The adaptation of Dianthus carthusianorum L. (Caryophyllaceae) to growth on a zinclead heap in southern Poland. Plant and Soil, 24, 249-257.

Zdraveva, P., Pencheva, I., Popova, P., Ionkova, I., \& Krasteva, I. (2015). Production of saponarin in in vitro cultures of Gypsophila species. Journal of Chemical and Pharmaceutical Research, 1, 829-832.

Zheng, Y., Xu, W., He, Z., \& Ma, M. (2007). Plant regeneration of the arsenic hyperaccumulator Pteris vittata L. from spores and identification of its tolerance and accumulation of arsenic and copper. Acta Physiologiae Plantarum, 30, 249-255. 